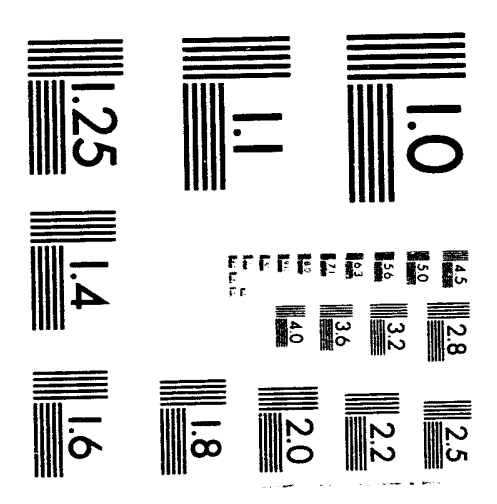



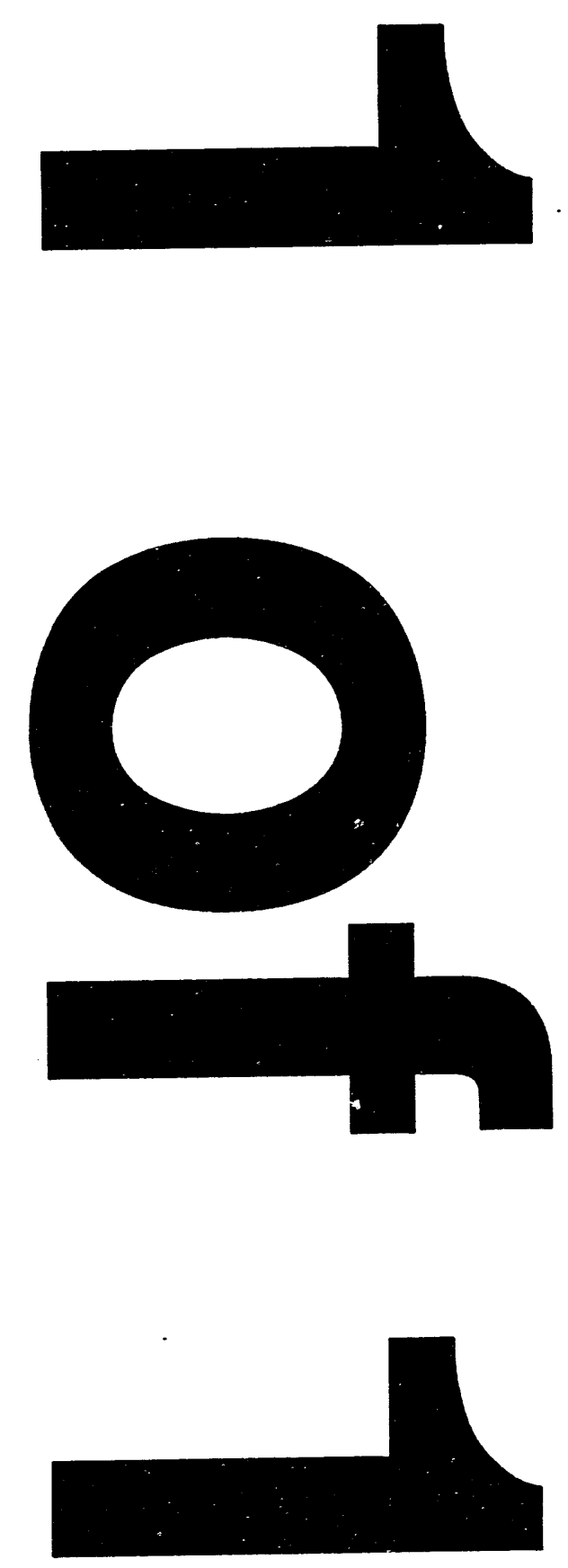


\section{The "Derived-from" Rule under the Resource Conservation and Recovery Act (RCRA)}

BACKGROUND: Under the "Derived-from" rule, solid waste that is generated from the treatment, storage or disposal of a hazardous waste is itself classified as a hazardous waste. Therefore, residues resulting from treatment, storage or disposal activities including materials such as sludges, ash emission control dusts, leachate, or spill residues are considered hazardous wastes (with certain exceptions discussed below). This provision is based on the premise that any residues from treatment, storage or disposal of hazardous waste will contain hazardous constituents [40 CFR 261.3(C)(2)(i)].

It should be noted that a December, 1991 court ruling remanded both the "Mixture" rule (see ref. 1) and the "Derived-from" rule to the Environmental Protection Agency (EPA), on the grounds that EPA did not allow for public comment on these rules prior to promulgation. On March 3, 1992 EPA reinstated the rules on an interim basis, and is currently developing a revised regulatory scheme for hazardous waste classification (see ref. 2)

STATUTE: The Resource Conservation and Recovery Act.

REGULATIONS: 40 CFR 261.3(c) \& (d).

REFERENCES: 1. "The Mixture Rule Under RCRA," EH-231 Information Brief, EH-231-005/0991, September 1991.

2. Federal Register Notice (57 FR 7628, 3/3/92).

3. Federal Register Notice (45 FR 33096, 5/19/80).

4. Federal Register Notice (56 FR 7197), February 21, 1991.

5. Obtaining Variances from the Treatment Standards of the RCAA Land Disposal Restrictions, EH231 Guidance Manual, EGD (RCRA)-001/0590, May 1990.

6. Federal Register Notice (55 FR 22537), June 1, 1990.

What is a hazardous waste under RCRA?

A hazardous waste under RCRA is any solid waste that is not specifically excluded from the hazardous waste regulations, and that:

$\square$ is listed in one of four lists developed by EPA and contained in the Code of Federal Regulations (CFR) at 40 CFR 261.31-33 (a listed waste); and/or

a exhibits one or more of four characteristics identified at 40 CFR 261.21-24-ignitability, corrosivity, reactivity, and toxicity (a characteristic waste).

Furthermore, as stated in the background section above, under the "Derived-from" rule, solid waste that is generated from the treatment, storage or disposal of a hazardous waste is also classified as a hazardous waste.

With respect to treatment of hazardous wastes, does the "Derived-from" rule only apply to the waste stream remaining after all treatment steps have been completed?

No. For example, if solvents are treated using filters to separate out solid fines, the solid fines and the used filters are hazardous wastes, as they both constitute a solid waste generated from treatment, storage or disposal of a hazardous waste.

Does the "Derived-from" rule apply to materials reclaimed from non-hazardous solid wastes?

The "derived-from" rule only applies to wastes derived from hazardous wastes. Materials that are reclaimed from non-hazardous solid wastes are not wastes if used beneficially. However, if the reclaimed material is burned for energy recovery or applied to the land in a manner constituting disposal (e.g., dust suppression) it is a solid waste [ 40 CFR 261.3(c)(2)(i)]. Because such a material burned for energy recovery or used in a manner constituting disposal is a solid waste, one must alsc consider the possibility that it may exhibit a characteristic of a hazardous waste, which would render it a hazardous waste as well.

Are there exclusions from the "Derived-from" rule?

The regulation exempts wastes derived from the treatment of characteristic waste. provided they no longer exhibit the hazardous characteristic after treatment. It is important 
to note that wastes listed solely on the basis of their characteristics are not eligible for this exclusion, because they are listed hazardous wastes. They would remain listed hazardous wastes after treatment, even if they no longer exhibit the characteristic. This differs from the mixture rule, in that wastes listed solely on the basis of exhibiting a characteristic are not hazardous if they are mixed with a non-hazardous solid waste, and thus rendered non-hazardous (see ref. 1).

Furthermore, the following four types of waste are not hazardous wastes under the "Derived-from" rule unless they exhibit a characteristic of a hazardous waste [40 CFR 261.3(c)(2)(ii)(A-C)]:

\section{- Lime Stabilized Waste Pickle Liquor Sludge From the} Iron and Steel Industry-This applies only to the iron and steel industry, and only to those wastes treated by lime stabilization.

a Combustion Residuals - Ordinarily, residue from burning of hazardous wastes are hazardous wastes under the "Derived-from" rule. However, if the combustion involves fossil fuel, or certain hazardous waste derived fuels, there may be exceptions to the rule. For example, combustion residuals of coal and other fossil fuels are exempt. This exclusion is also extended to combustion of certain fuels produced from petroleum industry wastes, petroleum coke, and iron and steel coke, and coal tar.

K061, K062, and F006 Treatment Residuals-This exclusion applies to non-wastewater residues, such as slag, resulting from high temperature metal recovery (HTMR) processing of certain listed wastes. Those wastes are:

o K061 wastes (emission control dust/sludge from the primary production of steel in electric furnaces),

- K062 wastes (spent pickle liquor generated by steel finishing operations of facilities within the iron and steel industries), and

F006 wastes (wastewater treatment sludges from certain electroplating operations).

In order for this exclusion to apply, concentrations of hazardous constituents must not exceed levels identified in 40 CFR 261.3(c)(2)(ii)(C). Notification and certification requirements apply to all shipments of such wastes to subtitle $D$ disposal units.

Finally, precipitation run-off from hazardous waste facilities is exempt from regulation. This is based on the presumption that precipitation run-off will not have had sufficient contact with the waste to solubilize hazardous constituents. However, collected run-off would be a solid waste, and could possibly be hazardous as well (see ref. 3 ).

\section{What is the "Bevill" exclusion, and how might it apply to "Derived-from" wastes?}

The "Bevill" amendment exempts certain wastes specified under RCRA 3001(b)(3)(A)(i-iii) from regulation as
RCRA hazardous wastes, under certain conditions. Those wastes are fly ash and bottom ash wastes, slag wastes and flue gas emission control wastes generated from combustion of coal or other fossil fuels, certain mining wastes, and cement kiln dust waste.

This exemption is in effect pending completion of an EPA report to Congress and a subsequent regulatory determination on whether this exemption is warranted. The report to Congress is required under RCRA Section 8002(a). The subsequent regulatory determination is required under RCRA Section $3001(b)(3)(C)$.

It is EPA's current position that the residues derived from the treatment of these wastes are themselves excluded from regulation, so long as treatment does not significantly change the character of the wastes as being "high volume/low hazard" wastes (see ref. 4).

\section{If the above exclusions do not apply to a "Derived-from" waste, is it possible to petition for an exemption from regulation?}

If the treatment residues are derived from a listed waste, it is possible to apply for a delisting petition under $40 \mathrm{CFR}$ 260.20 and 260.22 [40 CFR 261.3(d)]. However, a waste so excluded may still be a hazardous waste if found to exhibit a characteristic of a hazardous waste.

\section{If a hazardous waste is treated to meet Land Disposal Restrictions (LDR) treatment standards, can the treatment residues (i.e. the "Derived-from" wastes) be land disposed?}

All wastes generated in the course of treatment are prohibited from land disposal unless they comply with the LDR treatment standards, or are otherwise exempted from the LDR requirements, either through a no-migration determination or an extension to the LDR effective date based on the lack of adequate capacity (i.e., national capacity variance or case-by-case extension). Thus, treatment residues that meet LDR treatment standards can be land disposed. It is also possible to petition EPA for a variance from the treatment standards (see ref. 5). However, it is EPA's position that since treatment standards are generally based on concentrated forms of a waste (i.e., the original waste), the residues from subsequent treatment should be easier to treat (see ref. 6).

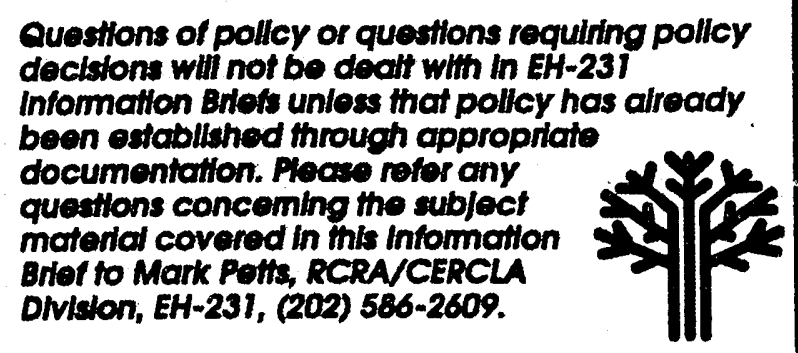



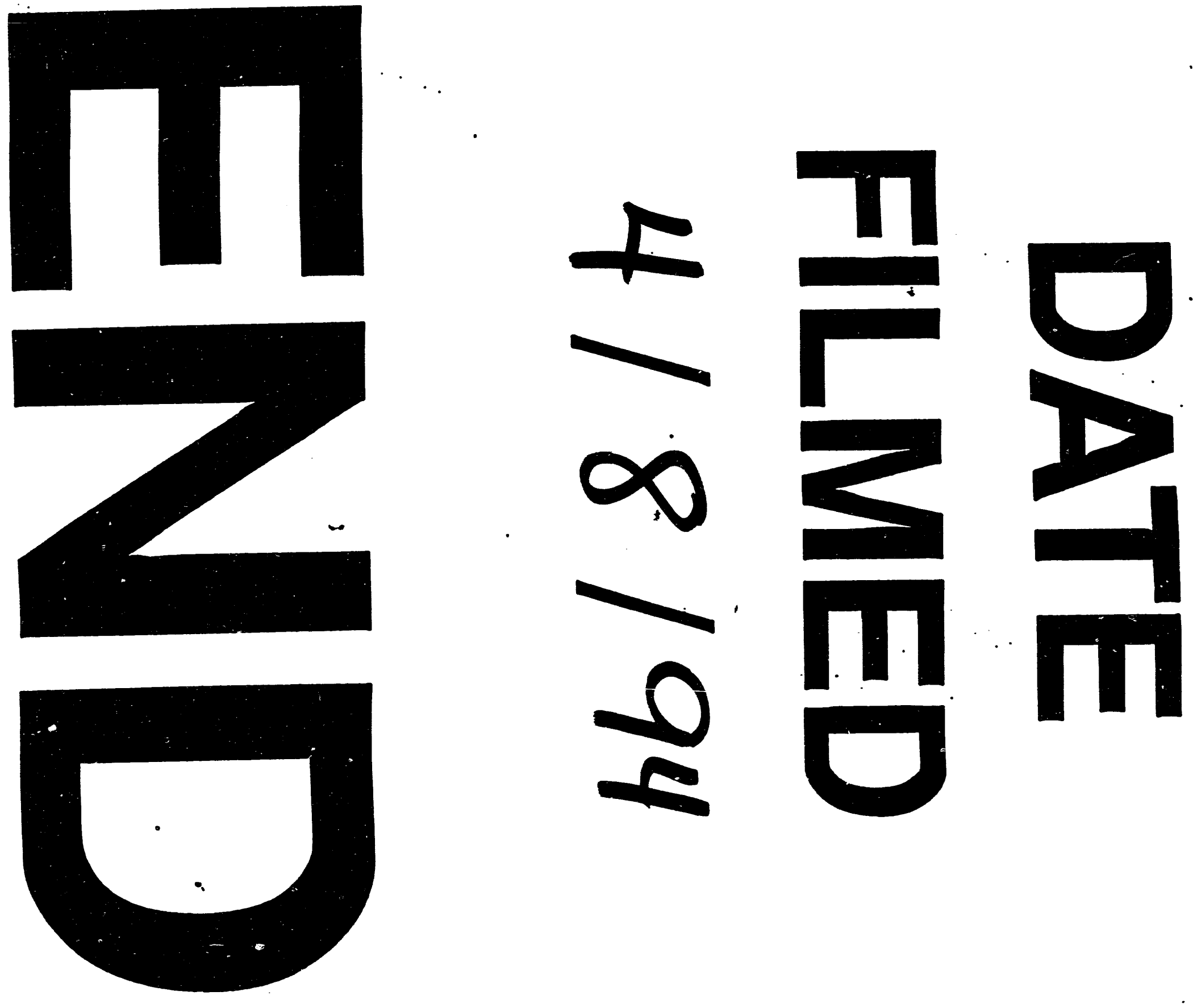
